\title{
Application of Multilevel Latent Class Analysis to Identify Achievement and Socio-Economic Typologies in the 20 Wealthiest Countries
}

\author{
W. Holmes Finch ${ }^{1} \&$ Gregory J. Marchant ${ }^{1}$ \\ ${ }^{1}$ Educational Psychology, Ball State University, USA \\ Correspondence: W. Holmes Finch, Department of Educational Psychology, Muncie, IN, 47304, USA. E-mail: \\ whfinch@bsu.edu
}

Received: December 21, 2012

Accepted: February 17, $2013 \quad$ Online Published: April 11, 2013

doi:10.5539/jedp.v3n1p201

URL: http://dx.doi.org/10.5539/jedp.v3n1p201

\begin{abstract}
There has been increased interest in cross-national comparisons of educational achievement, particularly using the data provided through the Programme for International Student Assessment (PISA). The growing tendency in the popular media is to characterize such comparisons by ranking nations based upon mean achievement test scores. However, recent work has demonstrated that the way in which students are organized in schools has a impact on student achievement. The current study demonstrated the utility of a relatively new statistical technique, the nonparametric latent class model, to investigate the cross national organization of schools and its relationship to student achievement and socio-economic status. The results demonstrated that indeed, it is not enough to simply compare mean achievement performance across countries, but rather that the ways in which nations organize students into schools is also associated with test performance. The results of this study highlight both the importance of understanding school organizational context, and the analytic power of the nonparametric latent class model.
\end{abstract}

Keywords: PISA, multilevel latent class analysis, academic achievement

\section{Introduction}

The role of school structure and the distribution of students within schools is an area of increasing research interest to those concerned with educational policy. In particular, research has demonstrated that the distribution of students by socio-economic status (SES) and achievement level is directly related to the academic performance of individual students within countries (Dronkers \& Levels, 2007; Caldas \& Bankston, 1997). Put another way, the overall school context matters when it comes to individual student achievement (De Fraine, van Damme, van Landeghem, Opdenakker, \& Onghena, 2003). For example, research has shown that students who come from a relatively low SES background are likely to have higher academic achievement if they attend schools that have relatively higher mean SES than will those with similar SES attending low SES schools (Opdenakker \& van Damme, 2001). Similarly, lower SES students attending schools with relatively higher mean achievement have demonstrated higher mean achievement than those of comparable background attending lower achieving schools (Organization for Economic Co-operation and Development (OECD), 2007). These patterns have been witnessed across multiple countries with a variety of academic achievement measures.

\subsection{School Organization and Achievement}

Recently there has been a great deal of interest in identifying the relative success of countries in terms of educational achievement. Boasting about one's school probably dates back to the beginning of schools, just as boasting about one's country probably dates back to the creation of the second country. Claims of more "spirit" and being \#1 have been replaced by serious efforts to compare schools and countries by using testing. In an attempt to better understand international differences in educational performance and the contexts that impact it, the Programme for International Student Assessment (PISA) has been testing thousands of (15 year-old) students in over 65 countries for much of the last decade. Recent reports herald Finland as the winner in the international race to the top in education. Headlines proclaim: "Finnish far ahead of U.S. schools (Rubenstein, 2012)," "Schools we can envy (Ravitch, 2012)," and "What is it about Finland (Mansell, 2011)?" Much of the PISA research suggests that socioeconomic status (SES) might play a role in the academic success for Finland and 
other countries (Chia \& Xihua, 2008; Milford, Ross, \& Anderson, 2010). Chia and Xihua (2008) found that a $10 \%$ increase in family SES was associated with a five-point increase in PISA mathematics scores with a similar relationship in science. Among students in the U.S and Canada, an SES increase of one standard deviation equated to a 27-point increase on the scientific literacy portion of the 2006 PISA (Milford, Ross, \& Anderson, 2010). Of the variables associated with family SES, parent education stands out as being strongly connected to student achievement (Hakkinen, Kirjavainen, \& Uusitalo, 2003; Schreiber, 2002). Education systems are recognizing the needs of students not speaking the native language of the country. Achievement tests given in students' second language yield depressed scores that may not be valid measures of their knowledge (Abedi \& Lord, 2001); Abella, Urrutia, \& Shneyderman, 2005). With an increasing awareness of the importance of the nature of students in schools within countries comes the need for analyses that can consider variables such as SES across multiple levels.

Who's \#1 isn't just about the quality of the educational system; i.e., curriculum, teachers, school buildings. It is also about the students in the schools, in the countries that take the test. These individual students have a background of possessions and family characteristics as well as their level of academic achievement. In other words, the schools are a collective of students who have differing levels of SES and academic achievement. Therefore, in order to truly understand the relative educational performance for a country, it is perhaps first necessary to understand the students that make up the aggregate for each country. Only after these student qualities are fully taken into account can the relative merits of the various education systems themselves be considered. As discussed above (Dronkers \& Levels, 2007; De Fraine, van Damme, van Landeghem, Opdenakker, \& Onghena, 2003; Caldas \& Bankston, 1997), the ways in which students are organized into schools is directly related to their performance on standardized achievement tests.

The purpose of this paper it is to reports a statistical effort to identify the types of students that can be found within the 20 wealthiest nations participating in PISA, and to characterize how they are grouped within different types of schools. In addition, the study described herein demonstrates the utility of multilevel latent class analysis in describing the latent structure for data at multiple levels in a hierarchy (e.g., students within schools). We hope that the resulting student and school profiles will serve to inform policy makers and others regarding some baseline factors that play a role the performance of countries' education systems. These profiles can be seen as inherent in the populations of these nations, and are factors that must be dealt with by their education systems. Using multilevel latent class analysis (MLCA), individuals and schools were grouped by examinee level achievement and economic status data. Subsequently, the countries were clustered by the prevalence of these student and school latent classes. This multilevel clustering allowed for comparisons of relative success, wealth, and other characteristics that shape the "spirit" of success for schools and countries.

\subsection{Multilevel Latent Class Analysis}

Latent class analysis (LCA) identifies latent groups in the population based on a set of observed variables, and is typically conducted in an exploratory manner with no a priori hypotheses regarding the number or nature of the latent classes, much in the way that cluster analysis is frequently used (Hoijtink, 2001). Typically, several LCA models are fit to the data, each differentiated by the number of latent classes, and models are compared via fit indices. Determination of the optimal solution involves finding a statistically good fitting model that produces substantively meaningful classes.

A primary assumption underlying standard LCA models is that individual observations are independent of one another, given their membership in a specific latent class (Vermunt \& Magidson, 2002). However, in many applications, particularly in educational research, participants (level-1) are sampled in clusters such as classrooms or communities (level-2), inducing correlated data among observations from the same clusters (Asparouhov \& Muthén, 2008). When such data structures are present, models that account for this dependence should be used so as to avoid parameter estimation inaccuracy, biased standard errors, and inflated Type I error rates for hypothesis tests regarding the parameters (Asparouhov \& Muthén; Vermunt, 2003; 2008). A number of such models have been described in the literature, along with examples of their application in practice (e.g., Gilthorpe et al., 2011; Montanari et al., 2010). However, relatively less methodological attention has been given to their performance in regards to parameter estimation, and the quality of their classification of individuals at level-1. The primary goal of this study was to ascertain how well each of these models could recover parameter values at level-1, as well as the quality of group classification. Henry and Muthén (2010) provide a thorough description of these models. Therefore, what follows is a condensed review of the MLCA models that were used in this study, and the interested reader is encouraged to refer to the work by Henry and Muthén.

There exist a number of MLCA models that can be used with multilevel data. The four major versions are 
outlined in Henry and Muthén (2010). Finch and French (2011) conducted a simulation study comparing the relative performance of these models in terms of their ability to adequately fit the data and accurately group individuals into the appropriate latent classes. They found that the nonparametric model (Vermunt, 2008; Bijmolt, Paas, \& Vermunt, 2004) was generally the optimal approach across a wide range of study conditions. The nonparametric model (Figure 1) allows for both level-1 (e.g., student) and level-2 (e.g., school) latent classes.

\section{Level-1}
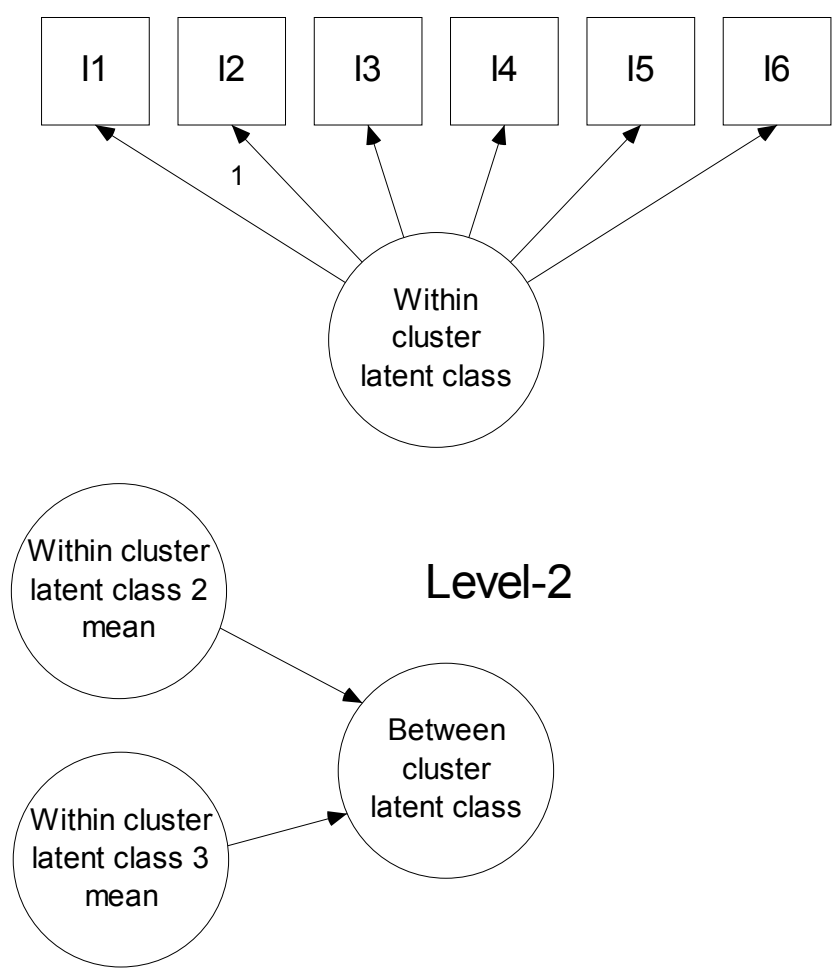

Figure 1. Nonparametric multilevel latent class model

The model works in such a way that first level-1 classes are identified within clusters (schools), and then the means of these within cluster latent classes are used as indicators for the level-2 latent class analysis. Therefore, if students at level-1 are grouped based on reading, math, and science achievement scores, along with a measure of SES, the latent class means at the school level are in turn used in a latent class analysis focused on the schools themselves (level-2). The final result of this analysis yields separate latent classes for both level-1 and level-2, with the probability of an individual being in a specific level-1 class differing across the level-2 classes. Figure 1 provides a visual example of the nonparametric MLCA model.

In addition to providing information regarding the multilevel latent class structure, MLCA also allows for the inclusion of covariates that might predict latent class membership at both levels. Therefore, in our example we might have variables measured at the individual student level that predict membership in the level-1 latent class, such as language status (e.g., native speaker or not). In addition, we could also have school level covariates (e.g., minutes spent in specific type of instruction) that could predict school membership in a level-2 latent class. The inclusion of covariates at each level allows for greater explanation of the classes that result from the MLCA.

\subsection{Goals of the Current Study}

In the current study the nonparametric MLCA model was used to identify latent classes of students based on three achievement test scores and a measure of socio-economic status (SES), and to identify latent classes of schools based on the types of students they contain. More precisely, the goal of this research was twofold: (1) Demonstrate the great utility of the nonparametric MLCA model for simultaneously identifying student and school level latent classes as a means for understanding different ways in which students are grouped within schools, and how such organization might be linked to achievement and SES, and (2) Explore cross-national 
patterns of student/school organization based on academic achievement and SES. Prior research has demonstrated that the way in which schools organize their students has an impact on individual student performance (Alegre \& Ferrer, 2010). However, very little work has been done to provide insights into how different nations deal with such school organization issues, making cross-national achievement comparisons somewhat unclear, as apparent differences in mean test scores may be related as much (or more) to how students are organized into schools, as opposed to actual differences in education quality. In particular, a major focus of interest in this study was the investigation of the ways in which students were grouped in schools differed cross nationally in terms of academic performance and SES. In other words, did some nations group students with disparate achievement and SES backgrounds together, while others grouped students in a more homogeneous fashion? Finally, in order to bring greater clarity to the issue of how the world's 20 wealthiest nations were similar and different with regard to this organization issue, cluster analysis at the national level was carried out, based upon the student and school level organization results. Given these two broad goals, it is our hope that by describing the methods and results from the current study, we will provide researchers with an additional methodology they can use to learn more about the interplay of school structure and its relationship to student achievement. We also hope to provide greater insights into how student-school organization is related to student achievement and SES. These results may help to inform researchers regarding alternative ways in which student performance on large scale assessment efforts such as PISA can be compared across nations.

\section{Method}

The sample included a total of 167,767 15-year old students (Organization for Economic Cooperation and Development (OECD), 2009) from the 20 nations having the highest GDP and a population over four million (see Figure 2 for countries and scores).

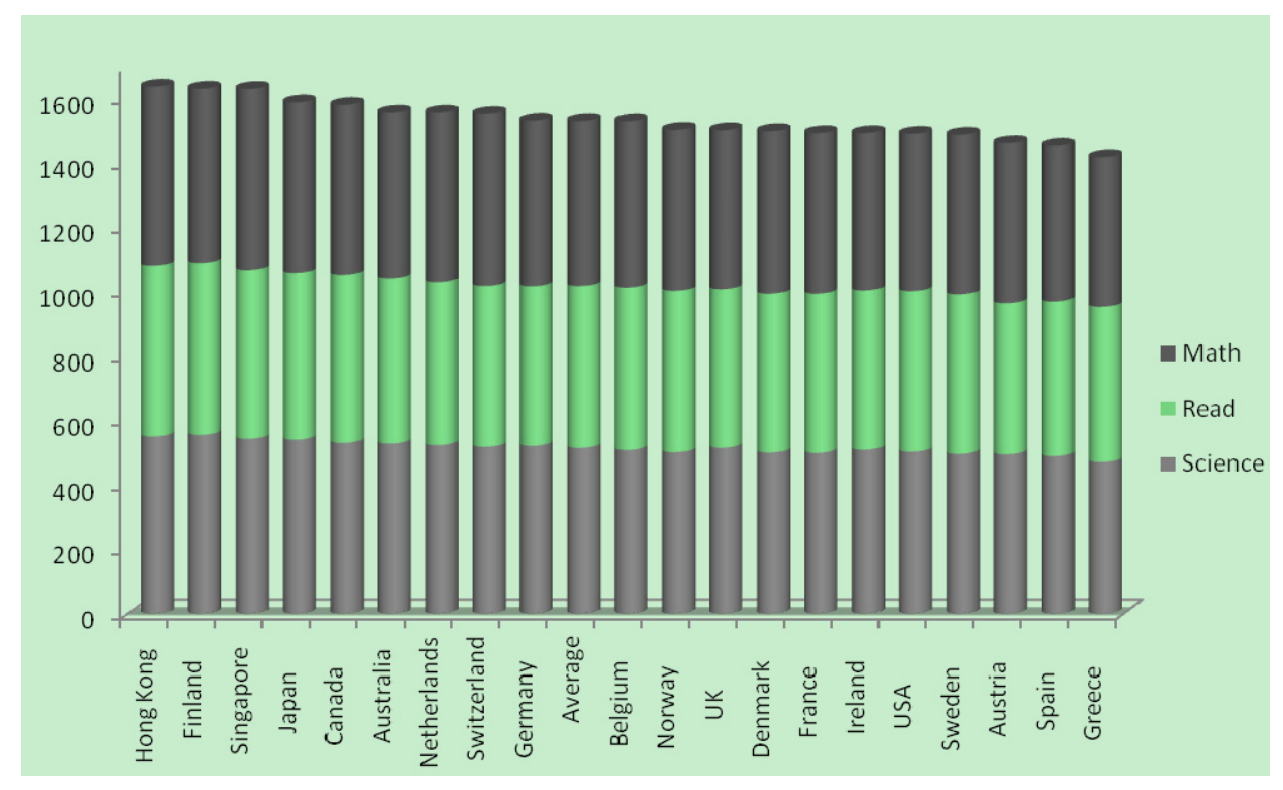

Figure 2. PISA (2009) scores by country

This is a common approach to country selection that eliminates extreme national poverty as an educational quality factor (e.g., Equity Trust, 2010). The sample is weights to be representative of each country and for each school. Of the participants included in this study, 50.7\% were male. Nonparametric MLCA (Henry \& Muthén, 2010) was conducted with MPlus version 6.11 software (Muthén \& Muthén, 2011) using reading, math, and science achievement scores and the International Socio-Economic Index of Occupational Status (SES). The SES index includes the highest level of education of the student's parents, the PISA index of home educational resources, and the PISA index of family possessions (OECD, 2010). It has a mean of 0 and standard deviation of 1 , so that individuals with positive values are in families with above average wealth and those with negative values are in families with below average wealth. Students were nested in schools, creating a multilevel data structure, as described above. In addition to controlling for within school variability, the nonparametric MLCA 
also provided identification of school latent classes, thereby yielding information about patterns of both student and school achievement/SES. Finally, covariates at both level-1 and level-2 were also included in the analysis in order to demonstrate the added utility of this feature of MLCA, and to provide further explanation regarding the nature of the latent classes. At the student level, both language status (native speaker of the language in which the test was given, yes/no), and parental education level (number of years of education) were included. At the school level, the mean number of minutes of language, mathematics, and science instruction per week, as reported by students, were included. Student sampling weights were used in all analyses.

\section{Results}

Prior to conducting the MLCA, the correlation matrix of the variables used in the latent class analysis was first examined (see Table 1 for the variable list) in order to provide descriptive information regarding the data at hand. In addition, descriptive statistics for the variables used in MLCA model estimation were also examined, and appear in the tables, as will be discussed below. The correlation values revealed strong relationships among the three achievement variables, as would be expected, with all coefficients between 0.88 and 0.93 . In addition, the correlation between each of the achievement variables and SES was also estimated, with all of them between 0.38 and 0.39 , suggesting a moderately positive relationship between family financial resources and student achievement and indicating that SES was associated with approximately $15 \%$ of the variation in achievement test scores.

Table 1. Average of individuals from all countries for five student latent classes: Percent of each student cluster, SES index, and Math, Reading, and Science score (standard deviation) for each student cluster

\begin{tabular}{|c|c|c|c|c|c|c|c|}
\hline & Lowest & Low & Median & High & Highest & Total & Rank \\
\hline \multicolumn{8}{|l|}{ Overall } \\
\hline Percent & 7 & 21 & 30 & 28 & 14 & & \\
\hline SES & $-.56(.85)$ & $-.29(.83)$ & $.02(.84)$ & $.38(.81)$ & $.73(.76)$ & $.12(.90)$ & \\
\hline Math & $336(41)$ & $416(34)$ & 487 (32) & $558(33)$ & $636(37)$ & $502(90)$ & \\
\hline Read & $322(46)$ & 414 (37) & $491(35)$ & $563(34)$ & $636(37)$ & $502(94)$ & \\
\hline Science & $328(42)$ & $419(31)$ & 498 (29) & $574(29)$ & $653(34)$ & $511(96)$ & \\
\hline \multicolumn{8}{|l|}{ Cluster 1} \\
\hline Percent & 5 & 14 & 25 & 34 & 22 & & \\
\hline SES & $-.46(.73)$ & $-.38(.76)$ & $-.22(.76)$ & $.04(.75)$ & $.28(.71)$ & $-.05(.78)$ & 4 \\
\hline Math & $342(50)$ & $426(33)$ & $493(31)$ & $562(33)$ & $646(40)$ & $532(90)$ & 1 \\
\hline Read & $302(53)$ & $406(38)$ & 485 (34) & $559(34)$ & $632(39)$ & $522(96)$ & 1 \\
\hline Science & $322(50)$ & $423(31)$ & $503(29)$ & $578(27)$ & $655(35)$ & $541(95)$ & 1 \\
\hline \multicolumn{8}{|l|}{ Cluster 2} \\
\hline Percent & 4 & 16 & 30 & 33 & 17 & & \\
\hline SES & $-.26(.83)$ & $-.01(.79)$ & $.26(.77)$ & $.54(.75)$ & $.87(.72)$ & $.40(.82)$ & 1 \\
\hline Math & $338(42)$ & $422(35)$ & $492(34)$ & $564(34)$ & $642(38)$ & $523(87)$ & 2 \\
\hline Read & $316(45)$ & 409 (36) & $488(35)$ & $563(34)$ & $639(38)$ & $518(91)$ & 2 \\
\hline Science & $324(42)$ & $418(31)$ & $494(31)$ & $571(30)$ & $653(37)$ & $527(91)$ & 2 \\
\hline \multicolumn{8}{|l|}{ Cluster 3} \\
\hline Percent & 9 & 20 & 27 & 29 & 15 & & \\
\hline SES & $-.67(87)$ & $-.38(.80)$ & $-.04(.78)$ & $.33(.77)$ & $.72(.76)$ & $.07(.89)$ & 3 \\
\hline Math & $338(44)$ & $420(36)$ & 492 (34) & $566(32)$ & $642(36)$ & $508(95)$ & 3 \\
\hline Read & $317(50)$ & $410(37)$ & $486(36)$ & $557(35)$ & $624(37)$ & 497 (97) & 3 \\
\hline
\end{tabular}




\begin{tabular}{rlllllll}
\hline $\begin{array}{r}\text { Science } \\
\text { Cluster } 4\end{array}$ & $324(45)$ & $419(32)$ & $498(28)$ & $571(29)$ & $648(34)$ & $510(99)$ & 3 \\
Percent & 8 & 24 & 32 & 26 & 10 & & \\
SES & $-.55(.86)$ & $-.27(.85)$ & $.07(.86)$ & $.48(.82)$ & $.94(.70)$ & $.14(.93)$ & 2 \\
Math & $334(38)$ & $413(34)$ & $484(31)$ & $552(32)$ & $627(34)$ & $488(86)$ & 4 \\
Read & $328(42)$ & $416(36)$ & $494(34)$ & $568(33)$ & $644(35)$ & $497(93)$ & 4 \\
Science & $331(38)$ & $418(30)$ & $497(29)$ & $574(29)$ & $656(32)$ & $502(93)$ & 4 \\
\hline
\end{tabular}

Using the sample-size adjusted Bayesian Information Criterion fit statistic (aBIC), the optimal solution for the MLCA was determined to include five student level and four school level latent classes. In addition, both student and school level covariates were related to the student and school latent class variables. Following is a description of both the student and school level latent classes, and the relationship of the covariates with each type of latent class. Once the student and school latent classes were identified, HCA was used twice to identify clusters of countries based upon the distribution of student and school classes, respectively. In other words, the proportion of each of the five classes of students was entered into the HCA algorithm in order to identify country clusters based on student profiles. Similarly, HCA was used with the prevalence of school level classes as the variables in order to identify clusters of countries based on the types of schools that they have. The purpose of the HCA was to gain insights into cross-national differences in cluster makeup.

\subsection{Student Latent Classes}

The multilevel latent class analysis identified five student level latent classes. Based upon the pattern of achievement and SES, the classes were identified as those with the Lowest achievement/SES, those with Low achievement/SES, those with a Median level, individuals with High achievement/SES values and finally those with the Highest values on all of the measures (see Table 1). The distribution of students across the clusters yielded a slight negatively skewed distribution with almost $80 \%$ of the students in the middle three clusters, $7 \%$ in the lowest cluster, and twice that in the highest cluster.

Both of the student level covariates, native language status and parental education, were significantly related to the student level latent class. The reference category in this analysis was the fifth latent class, which had the highest mean achievement and SES values. Table 2 includes the slope, standard error, test statistic, and $p$-value for language and parental education for each of the first four student level latent classes.

Table 2. Results for student level covariates

\begin{tabular}{lllll}
\hline Variable & Slope & Standard error & Test statistic & $p$ \\
\hline Within 1 & & & & \\
Language & -0.826 & 0.037 & -22.568 & 0.000 \\
Parental education & -0.164 & 0.005 & -34.743 & 0.000 \\
Within 2 & & & -12.253 & 0.000 \\
Language & -0.371 & 0.030 & -23.465 & 0.000 \\
Parental education & -0.104 & 0.004 & & \\
Within 3 & & & 3.459 & 0.001 \\
Language & 0.165 & 0.048 & 16.779 & 0.000 \\
Parental education & 0.120 & 0.007 & & 0.000 \\
Within 4 & & & -29.251 & 0.000 \\
Language & -1.433 & 0.049 & -34.574 & \\
Parental education & -0.229 & 0.007 & & \\
\hline
\end{tabular}

Language was coded as 1 for native speakers of the language in which the test was given and 0 for non-native 
speakers. Parental education was coded as the number of years for the most highly educated parent. A negative slope value for a given latent class indicates that a higher value of the covariate was associated with a lower probability of being in that latent class versus latent class 5. For example, the parental education slope for latent class 1 was -0.164 , indicating that individuals whose parents had more years of education were less likely to be in latent class 1 than in latent class 5. Similarly, the slope for Language was -0.826 , which means that those who were native speakers of the language in which the test was given were less likely to be in latent class 1 than in latent class 5. In other words, examinees whose parents had more years of education and who were native speakers of the test language were more likely to be in the highest achieving and highest SES latent class. Similar results were evident for latent classes 2 and 4, but not 3. In the latter case, native speakers and those with higher education were more likely to be in latent class 3 than in class 5 .

In order to gain insights into cross-national patterns of latent class membership, the 20 nations were subsequently clustered based upon the distribution of the student latent classes (i.e., the percent of individuals in each latent class, see Tables 3-6 in the Appendix). The optimal solution was four clusters, based on the agglomeration index (Gordon, 1999). An examination of descriptive statistics for the clusters reveals that both Clusters 1 and 2 were comprised of nations with relatively few individuals in the Lowest and Low latent classes (see Table 1). With regard to patterns of performance on the achievement measures and SES, different patterns emerged. Perhaps most notable was the fact that Cluster 1 had the lowest mean SES of the four clusters, but the best overall mean performance on all of the achievement tests. Conversely, Cluster 4 had the second highest mean SES of the four clusters, but the lowest mean achievement scores. Further examination of SES reveals that Cluster 2 consistently displayed the largest values across student level latent classes, except in the Highest student class. Cluster 1, in turn, had the lowest SES mean for the Median, High and Highest groups. Such was not the case, however, for the Lowest and Low achievement/SES latent classes. In other words, Cluster 1 had the economically least advantaged students in the Median, High, and Highest latent classes; i.e., those with the highest achievement and most family resources. Indeed, the average student in the Highest latent class for Cluster 1 had economic resources roughly equal to those of a Cluster 2 student in the Median latent class, and well below those of Cluster 3 or 4 students in the High latent class. Despite having fewer resources however, the mean achievement test scores in the Highest student class for cluster 1 were comparable to or better than those of the other country clusters. Indeed, Cluster 1 consistently demonstrated among the best achievement test performance across latent classes categories, with the exception of Reading, where Cluster 4 did quite well, and for Science in the Lowest student latent class.

Table 3. Cluster 1 of 4 for countries by student clusters: Percent of each student cluster, SES index, and Math, Reading, and Science mean score (standard deviation) for each student cluster

\begin{tabular}{|c|c|c|c|c|c|c|c|}
\hline & Lowest & Low & Median & High & Highest & Total & Rank \\
\hline \multicolumn{8}{|l|}{ Hong Kong } \\
\hline Percent & 3 & 11 & 24 & 38 & 24 & & \\
\hline SES & $-1.40(.97)$ & $-1.22(.98)$ & $-1.05(.97)$ & $-.70(.98)$ & $-.44(1.0)$ & $-.80(1.02)$ & 20 \\
\hline Math & $339(40)$ & $424(34)$ & $499(33)$ & $577(34)$ & $663(40)$ & $556(90)$ & 2 \\
\hline Read & $331(39)$ & $413(35)$ & $488(33)$ & $556(32)$ & $624(35)$ & $533(81)$ & 3 \\
\hline Science & 334 (39) & 424 (29) & $501(27)$ & $572(28)$ & $646(35)$ & $549(83)$ & 2 \\
\hline \multicolumn{8}{|l|}{ Finland } \\
\hline Percent & 2 & 11 & 26 & 40 & 23 & & \\
\hline SES & $-.29(.93)$ & $.01(.81)$ & $.20(.77)$ & $.42(.74)$ & $.72(.65)$ & $.37(.78)$ & 3 \\
\hline Math & $348(41)$ & $425(33)$ & $492(33)$ & $561(33)$ & $634(35)$ & $541(77)$ & 3 \\
\hline Read & $316(42)$ & $404(36)$ & $485(35)$ & $561(35)$ & $633(35)$ & $536(83)$ & 2 \\
\hline Science & $334(37)$ & $421(30)$ & 499 (29) & $577(30)$ & $661(35)$ & $554(85)$ & 1 \\
\hline \multicolumn{8}{|l|}{ Singapore } \\
\hline Percent & 4 & 14 & 24 & 31 & 27 & & \\
\hline SES & $-1.01(.83)$ & $-.88(77)$ & $-.64(.76)$ & $-.36(.71)$ & $.02(.67)$ & $-.43(.80)$ & 19 \\
\hline Math & $351(44)$ & $435(35)$ & $511(35)$ & 587 (33) & $676(41)$ & $562(100)$ & 1 \\
\hline
\end{tabular}




\begin{tabular}{rrlllllll}
\hline & Read & $322(38)$ & $404(31)$ & $479(32)$ & $551(31)$ & $633(40)$ & $526(95)$ & 4 \\
\multirow{2}{*}{ Japan } & Science & $328(32)$ & $412(31)$ & $490(29)$ & $568(29)$ & $658(41)$ & $542(100)$ & 3 \\
& & & & & & & & \\
& Percent & 6 & 14 & 26 & 34 & 21 & & \\
SES & $-.40(.67)$ & $-.33(.71)$ & $-.17(.70)$ & $.09(.68)$ & $.33(.65)$ & $-.01(.72)$ & 15 \\
Math & $341(50)$ & $426(32)$ & $491(30)$ & $560(32)$ & $643(38)$ & $529(90)$ & 5 \\
Read & $300(54)$ & $406(37)$ & $485(34)$ & $559(34)$ & $633(39)$ & $520(97)$ & 6 \\
Science & $321(51)$ & $424(31)$ & $504(29)$ & $579(27)$ & $655(34)$ & $539(96)$ & 4 \\
\hline
\end{tabular}

Table 4. Cluster 2 of 4 for countries by student clusters: Percent of each student cluster, SES index, and Math, Reading, and Science score (standard deviation) for each student cluster

\begin{tabular}{rlllllll}
\hline \multicolumn{1}{rl}{ Lowest } & Low & Median & High & Highest & Total & Rank \\
\hline Canada & & & & & & & \\
Percent & 3 & 15 & 31 & 35 & 17 & & \\
SES & $-.16(.86)$ & $.12(80)$ & $.36(.79)$ & $.61(.77)$ & $.97(.73)$ & $.50(.83)$ & 1 \\
Math & $339(42)$ & $423(35)$ & $492(34)$ & $564(34)$ & $640(36)$ & $527(83)$ & 6 \\
Read & $321(44)$ & $411(37)$ & $489(34)$ & $565(35)$ & $640(37)$ & $524(87)$ & 5 \\
Science & $324(39)$ & $418(31)$ & $492(29)$ & $569(30)$ & $647(33)$ & $529(86)$ & 5 \\
Australia & & & & & & & \\
Percent & 6 & 17 & 29 & 31 & 17 & & \\
SES & $-209(.75)$ & $-.51(70)$ & $.201(70)$ & $.52(.68)$ & $.80(.65)$ & $.34(.75)$ & 4 \\
Math & $335(41)$ & $418(32)$ & $486(31)$ & $557(31)$ & $639(39)$ & $514(89)$ & 9 \\
Read & $311(41)$ & $409(35)$ & $489(34)$ & $563(33)$ & $643(38)$ & $515(96)$ & 7 \\
Science & $322(45)$ & $419(30)$ & $498(27)$ & $575(28)$ & $664(39)$ & $527(98)$ & 6 \\
Switzerland & & & & & & & \\
Percent & 6 & 18 & 29 & 31 & 16 & & \\
SES & $-.65(.79)$ & $-.37(.80)$ & $-.04(.79)$ & $.28(.79)$ & $.67(.79)$ & $.08(.88)$ & 12 \\
Math & $346(44)$ & $432(40)$ & $511(37)$ & $584(36)$ & $662(40)$ & $534(94)$ & 4 \\
Read & $319(40)$ & $403(39)$ & $479(38)$ & $550(37)$ & $619(38)$ & $500(90)$ & 11 \\
Science & $329(40)$ & $415(32)$ & $493(29)$ & $566(39)$ & $644(36)$ & $517(92)$ & 9
\end{tabular}

Table 5. Cluster 3 of 4 for countries by student clusters: Percent of each student cluster, SES index, and Math, Reading, and Science score (standard deviation) for each student cluster

\begin{tabular}{rlllllll}
\hline \multicolumn{1}{r}{ Lowest } & Low & Median & High & Highest & Total & Rank \\
\hline Netherlands & & & & & & & \\
Percent & 4 & 22 & 27 & 29 & 19 & & \\
SES & $-.50(.91)$ & $-.14(.84)$ & $.12(.77)$ & $.46(.76)$ & $.79(.71)$ & $.27(.86)$ & 7 \\
Math & $358(32)$ & $427(33)$ & $500(31)$ & $571(29)$ & $640(32)$ & $526(86)$ & 7 \\
Read & $350(36)$ & $410(32)$ & $479(31)$ & $553(30)$ & $625(33)$ & $508(86)$ & 8 \\
Science & $327(38)$ & $415(33)$ & $495(28)$ & $570(27)$ & $648(33)$ & $522(93)$ & 7 \\
Germany & & & & & & & \\
Percent & 8 & 20 & 27 & 30 & 16 & & \\
SES & $-.58(.90)$ & $-.35(.82)$ & $.06(.79)$ & $.44(.75)$ & $.81(.80)$ & $.18(.90)$ & 10 \\
\hline
\end{tabular}




\begin{tabular}{|c|c|c|c|c|c|c|c|}
\hline Math & $342(39)$ & $418(36)$ & $491(34)$ & $566(33)$ & $645(37)$ & $513(95)$ & 10 \\
\hline Read & $324(42)$ & $406(37)$ & $481(35)$ & 555 (134) & $616(36)$ & 497 (92) & 14 \\
\hline Science & $333(36)$ & $423(33)$ & $502(28)$ & $576(29)$ & $654(36)$ & $520(97)$ & 8 \\
\hline \multicolumn{8}{|l|}{ Belgium } \\
\hline Percent & 10 & 19 & 25 & 29 & 17 & & \\
\hline SES & $-.61(.85)$ & $-.27(.84)$ & $.04(.82)$ & $.48(.83)$ & $.85(.74)$ & $.20(.93)$ & 8 \\
\hline Math & $336(48)$ & $421(38)$ & 497 (34) & $571(34)$ & $649(34)$ & $515(101)$ & 8 \\
\hline Read & $325(50)$ & $413(36)$ & $490(34)$ & $564(33)$ & $632(33)$ & 506 (99) & 9 \\
\hline Science & $312(56)$ & 414 (34) & $492(29)$ & $564(28)$ & $639(32)$ & $507(102)$ & 12 \\
\hline \multicolumn{8}{|l|}{ France } \\
\hline Percent & 11 & 19 & 29 & 28 & 13 & & \\
\hline SES & $-.76(.85)$ & $-.53(.74)$ & $-.21(.74)$ & $.14(.74)$ & $.54(.68)$ & $-.13(.84)$ & 17 \\
\hline Math & $331(48)$ & $418(35)$ & 489 (33) & $563(32)$ & $637(36)$ & 497 (96) & 13 \\
\hline Read & $309(56)$ & 415 (37) & $492(36)$ & $566(35)$ & $636(36)$ & $496(103)$ & 16 \\
\hline Science & $318(48)$ & $418(31)$ & $494(28)$ & $565(27)$ & $642(32)$ & 498 (99) & 16 \\
\hline \multicolumn{8}{|l|}{ Austria } \\
\hline Percent & 12 & 24 & 28 & 26 & 10 & & \\
\hline SES & $-60(.87)$ & $-.24(.69)$ & $.05(.73)$ & $.41(.76)$ & $.69(.76)$ & $.06(.84)$ & 13 \\
\hline Math & $356(40)$ & $425(36)$ & $498(35)$ & $569(34)$ & $643(34)$ & $496(92)$ & 14 \\
\hline Read & $311(41)$ & $399(38)$ & 477 (37) & $549(35)$ & $615(36)$ & 470 (97) & 20 \\
\hline Science & $330(41)$ & $422(31)$ & $500(29)$ & $573(27)$ & $651(31)$ & $494(98)$ & 18 \\
\hline
\end{tabular}

Table 6. Cluster 4 of 4 for countries by student clusters: Percent of each student cluster, SES index, and Math, Reading, and Science score (standard deviation) for each student cluster

\begin{tabular}{rlllllll}
\hline \multicolumn{1}{r}{ Lorway } & Lowest & Low & Median & High & Highest & Total & Rank \\
Percent & 6 & 22 & 35 & 29 & 9 & & \\
SES & $-.09(.78)$ & $.20(.76)$ & $.45(.68)$ & $.65(.65)$ & $1.00(.60)$ & $.47(.74)$ & 2 \\
Math & $343(36)$ & $419(34)$ & $488(32)$ & $559(32)$ & $632(31)$ & $498(80)$ & 12 \\
Read & $326(42)$ & $417(38)$ & $495(36)$ & $571(35)$ & $643(32)$ & $503(88)$ & 10 \\
Science & $328(35)$ & $413(31)$ & $491(28)$ & $567(29)$ & $644(28)$ & $500(85)$ & 14 \\
United K. & & & & & & & \\
Percent & 7 & 23 & 33 & 27 & 12 & & \\
SES & $-.32(.74)$ & $-.20(.72)$ & $.13(.72)$ & $.48(.71)$ & $.80(.64)$ & $.20(.79)$ & 9 \\
Math & $336(43)$ & $416(32)$ & $483(30)$ & $550(31)$ & $624(33)$ & $492(83)$ & 16 \\
Read & $316(47)$ & $408(35)$ & $487(34)$ & $550(33)$ & $636(35)$ & $494(92)$ & 17 \\
Science & $329(43)$ & $422(32)$ & $505(29)$ & $582(29)$ & $664(33)$ & $514(95)$ & 10 \\
Denmark & & & & & & & \\
Percent & 6 & 22 & 35 & 29 & 8 & & \\
SES & $-.51(.82)$ & $-.10(.82)$ & $.24(.81)$ & $.64(.76)$ & $.89(.71)$ & $.30(.87)$ & 6 \\
Math & $343(40)$ & $425(34)$ & $495(34)$ & $566(33)$ & $641(34)$ & $503(81)$ & 11 \\
\hline
\end{tabular}




\begin{tabular}{|c|c|c|c|c|c|c|c|}
\hline Read & 332 (39) & $415(36)$ & $490(33)$ & $557(32)$ & $622(32)$ & $595(81)$ & 1 \\
\hline Science & $319(40)$ & $411(32)$ & 492 (29) & $568(30)$ & $651(32)$ & 499 (88) & 15 \\
\hline \multicolumn{8}{|l|}{ Ireland } \\
\hline Percent & 7 & 21 & 33 & 30 & 8 & & \\
\hline SES & $-.54(.79)$ & $-.32(.79)$ & $-.02(.78)$ & $.35(.78)$ & $.60(.75)$ & $.05(.85)$ & 14 \\
\hline Math & $321(48)$ & $414(32)$ & $482(31)$ & 549 (29) & $618(33)$ & 487 (82) & 18 \\
\hline Read & $305(58)$ & $413(36)$ & $492(35)$ & $566(34)$ & $634(35)$ & 496 (92) & 15 \\
\hline Science & $319(54)$ & $422(32)$ & $501(30)$ & $580(29)$ & $663(32)$ & $508(93)$ & 11 \\
\hline \multicolumn{8}{|l|}{ USA } \\
\hline Percent & 8 & 25 & 31 & 26 & 11 & & \\
\hline SES & $-.52(.83)$ & $-.24(.84)$ & $.09(.86)$ & $.51(.81)$ & $.99(.68)$ & $.17(.93)$ & 11 \\
\hline Math & $335(34)$ & $412(33)$ & $482(30)$ & $551(31)$ & $627(34)$ & 487 (86) & 17 \\
\hline Read & $332(38)$ & 417 (35) & 495 (33) & $570(32)$ & $648(34)$ & $500(94)$ & 12 \\
\hline Science & $333(35)$ & $418(30)$ & $496(28)$ & $574(29)$ & $655(32)$ & $502(94)$ & 13 \\
\hline \multicolumn{8}{|l|}{ Sweden } \\
\hline Percent & 8 & 22 & 33 & 27 & 10 & & \\
\hline SES & $-.37(.95)$ & $.01(.78)$ & $.31(.71)$ & $.59(.70)$ & $.92(.68)$ & $.33(.81)$ & 5 \\
\hline Math & $331(48)$ & 419 (34) & 487 (33) & $562(32)$ & 637 (36) & 494 (89) & 15 \\
\hline Read & $312(55)$ & $419(40)$ & 495 (34) & $569(36)$ & $644(37)$ & 497 (96) & 13 \\
\hline Science & $313(48)$ & $412(31)$ & $490(29)$ & $569(29)$ & $651(32)$ & $495(96)$ & 17 \\
\hline \multicolumn{8}{|l|}{ Spain } \\
\hline Percent & 9 & 25 & 36 & 25 & 5 & & \\
\hline SES & $-1.12(.94)$ & $-.72(.95)$ & $-.32(1.01)$ & $.211(.02)$ & $.61(.96)$ & $-.31(1.09)$ & 18 \\
\hline Math & $329(48)$ & $416(41)$ & $493(36)$ & $564(37)$ & 637 (34) & $483(87)$ & 19 \\
\hline Read & $322(50)$ & 416 (39) & $493(35)$ & $559(33)$ & $623(31)$ & $481(85)$ & 19 \\
\hline Science & $333(46)$ & $422(33)$ & 498 (32) & $568(31)$ & $639(30)$ & $488(84)$ & 19 \\
\hline \multicolumn{8}{|l|}{ Greece } \\
\hline Percent & 11 & 29 & 34 & 21 & 4 & & \\
\hline SES & $-.73(.84)$ & $-.32(.92)$ & $.04(.93)$ & $.48(.90)$ & $.82(.80)$ & $-.02(.99)$ & 16 \\
\hline Math & $332(48)$ & $413(36)$ & 483 (37) & $551(36)$ & $627(30)$ & $466(83)$ & 20 \\
\hline Read & $326(47)$ & $426(42)$ & $506(40)$ & $575(38)$ & $640(39)$ & 483 (92) & 18 \\
\hline Science & $326(47)$ & $413(32)$ & $490(31)$ & $561(29)$ & $638(30)$ & $470(86)$ & 20 \\
\hline
\end{tabular}

\subsection{School Latent Classes}

Based on the results of the MLCA it was possible to characterize the four groups of schools as those predominantly containing the Lowest performers with the lowest SES, Low performing schools with below average SES, High performing schools with above average SES, and finally schools containing the Highest performers with the highest SES mean (see Table 7). This pattern of school latent classes was generally similar to that for students. 
Table 7. Average of individuals from all countries for four school latent classes: Percent of each school cluster, SES index, and Math, Reading, and Science score (standard deviation) for each school cluster

\begin{tabular}{|c|c|c|c|c|c|c|}
\hline & Lowest & Low & High & Highest & Total & Rank \\
\hline \multicolumn{7}{|l|}{ Overall } \\
\hline Percent & 15 & 35 & 36 & 15 & & \\
\hline SES & $-.45(.82)$ & $-.11(.86)$ & $.34(.82)$ & $.61(.80)$ & $.12(.90)$ & \\
\hline Math & $410(73)$ & $471(73)$ & $529(70)$ & $597(62)$ & $502(90)$ & \\
\hline Read & 407 (83) & $475(80)$ & $531(76)$ & $590(62)$ & $502(94)$ & \\
\hline Science & $412(81)$ & $482(79)$ & $542(76)$ & $604(64)$ & $511(96)$ & \\
\hline \multicolumn{7}{|l|}{ Cluster 1} \\
\hline Percent & 12 & 21 & 36 & 32 & & \\
\hline SES & -.45 & $-.35(.73)$ & $-.03(.77)$ & $.25(.72)$ & $-.05(.78)$ & 4 \\
\hline Math & $419(78)$ & $477(66)$ & $534(62)$ & $609(60)$ & $532(90)$ & 1 \\
\hline Read & $396(94)$ & $469(75)$ & $529(69)$ & $594(62)$ & $522(96)$ & 1 \\
\hline Science & $418(92)$ & $484(74)$ & $550(68)$ & $612(61)$ & $541(95)$ & 1 \\
\hline \multicolumn{7}{|l|}{ Cluster 2} \\
\hline Percent & 4 & 31 & 52 & 13 & & \\
\hline SES & $-.26(.78)$ & $.12(.79)$ & $.47(.77)$ & $.90(.75)$ & $.40(.82)$ & 1 \\
\hline Math & $424(77)$ & $483(80)$ & $535(76)$ & $599(71)$ & $523(87)$ & 2 \\
\hline Read & $408(83)$ & 477 (86) & $533(80)$ & $590(71)$ & $518(91)$ & 2 \\
\hline Science & $421(82)$ & $485(85)$ & $540(79)$ & $601(73)$ & $527(91)$ & 2 \\
\hline \multicolumn{7}{|l|}{ Cluster 3} \\
\hline Percent & 24 & 23 & 26 & 27 & & \\
\hline SES & $-.48(.82)$ & $-.11(.80)$ & $.15(.79)$ & $.59(.79)$ & $.07(.89)$ & 3 \\
\hline Math & $404(68)$ & $474(63)$ & $538(62)$ & $597(58)$ & $508(95)$ & 3 \\
\hline Read & $391(75)$ & $466(65)$ & $531(63)$ & $583(56)$ & 497 (97) & 3 \\
\hline Science & $401(76)$ & $481(64)$ & $542(62)$ & $600(59)$ & $510(99)$ & 3 \\
\hline \multicolumn{7}{|l|}{ Cluster 4} \\
\hline Percent & 13 & 44 & 37 & 6 & & \\
\hline SES & $-.44(.84)$ & $-.10(.88)$ & $.47(.82)$ & $1.05(.66)$ & $.14(.93)$ & 2 \\
\hline Math & $410(74)$ & $468(75)$ & $523(72)$ & $582(65)$ & $488(86)$ & 4 \\
\hline Read & $421(83)$ & 477 (83) & $532(80)$ & 594 (69) & 497 (93) & 4 \\
\hline Science & $417(80)$ & $481(82)$ & $540(80)$ & $600(71)$ & $502(93)$ & 4 \\
\hline
\end{tabular}

The covariates for the school level latent classes were the mean number of minutes per week of language, mathematics, and science instruction reported by examinees (Table 8). 
Table 8. Results for school level covariates

\begin{tabular}{lllll}
\hline Variable & Slope & Standard error & Test statistic & $p$ \\
\hline Between 1 & & & & \\
Language & -0.023 & 0.002 & -13.847 & 0.000 \\
Mathematics & 0.013 & 0.002 & 7.590 & 0.000 \\
Science & 0.011 & 0.001 & 10.520 & 0.000 \\
Between 2 & & & & \\
Language & -0.009 & 0.001 & -6.875 & 0.000 \\
Mathematics & 0.007 & 0.001 & 5.743 & 0.000 \\
Science & 0.005 & 0.001 & 6.209 & 0.000 \\
Between 3 & & & & \\
Language & -0.004 & 0.001 & -2.942 & 0.003 \\
Mathematics & 0.001 & 0.001 & 0.976 & 0.329 \\
Science & -0.005 & 0.001 & -5.347 & 0.000 \\
\hline
\end{tabular}

For the level-2 latent classes, the reference category was latent class 4, the highest achieving/SES schools. The slope for minutes of language instruction were negative for all three latent classes, suggesting that more time devoted to language instruction was associated with a lower likelihood of a school being in latent classes 1, 2, and 3, respectively, versus 4 . In other words, schools in latent class 4 tended to devote more time to language instruction than did any of the other classes. On the other hand, more minutes of mathematics instruction was associated with a greater likelihood of a school being in latent class 1 or 2 , versus 4 . This variable was not associated with the probability of being in class 3. Finally, these results reveal that greater time devoted to science instruction was associated with a higher likelihood of a school being in latent class 1 or 2 as compared to class 4 . On the other hand, more minutes of science in the classroom was related to a lower probability of being in latent class 3 versus 4 . Summarizing these results, schools in latent classes 1, 2, and 3 spent less time (as reported by students) on language instruction than did latent class 4 . In addition, schools in classes 1 and 2 spent more time on mathematics and science than did class 4 , while latent class 3 spent less time on science instruction than did class 4.

As was true for the student level latent classes, the 20 nations under study were clustered based upon the distribution of the school latent classes. Four classes proved to be the optimal solution based upon the Agglomeration Index (Gordon, 1999), with country membership patterns similar to the student clusters (see Tables 9-12 in the Appendix). For example, nation Cluster 1 can be characterized as containing the largest percentage of the highest performing/SES schools, which when combined with the high group accounted for $68 \%$ of the schools in the nations contained in this cluster. In addition, this cluster, which contained Hong Kong, Japan, and the Netherlands, had a relatively smaller percentage of the Low and Lowest school latent class groups. Of particular note with respect to the measures themselves, is that this cluster had the highest mean scores for all three achievement tests, but also had the lowest mean SES. Cluster 2 was comprised of two nations, Finland and Canada, and is perhaps most notable for the near absence of the Lowest performing schools, as well as for having the largest percentage of the High performers (see Table 10). Indeed, the nations in this cluster had approximately $83 \%$ of students attending schools in either of the two middle classes (Low or High), with the majority in the High latent class. In terms of ranking, this was the most economically advantaged group, and exhibited the second highest means on all three achievement tests. Cluster 3 was comprised of Singapore, Germany, Belgium, France, and Austria, and was unique in having an approximately equal distribution of school types. In addition, the nations in this cluster were generally ranked near the middle in terms of SES and achievement test scores, with a ranking of 3 on all four variables examined. Finally, Cluster 4 included the largest number of nations, 10 including the United States, and was characterized as having the smallest percentage of the highest performing schools, and a relatively larger share of the Low schools in comparison to the other clusters. In addition, this cluster also demonstrated the lowest school level mean achievement test performance overall, but had the second highest mean SES. 
Table 9. Cluster 1 of 4 for countries by school clusters: Percent of each school cluster, SES index, and Math, Reading, and Science score (standard deviation) for each school cluster

\begin{tabular}{|c|c|c|c|c|c|c|}
\hline & Lowest & Low & High & Highest & Total & Rank \\
\hline \multicolumn{7}{|l|}{ Hong Kong } \\
\hline Percent & 6 & 22 & 32 & 40 & & \\
\hline SES & $-1.18(.97)$ & $-1.14(1.03)$ & $-.91(.94)$ & $-.48(1.00)$ & $-.80(1.02)$ & 20 \\
\hline Math & $436(76)$ & $487(77)$ & $548(70)$ & $614(66)$ & $555(90)$ & 2 \\
\hline Read & $422(73)$ & $472(71)$ & $528(62)$ & $587(55)$ & $533(81)$ & 2 \\
\hline Science & 434 (77) & 487 (73) & $545(64)$ & $603(57)$ & $549(83)$ & 2 \\
\hline \multicolumn{7}{|l|}{ Japan } \\
\hline Percent & 13 & 21 & 34 & 32 & & \\
\hline SES & $-.43(.69)$ & $-.28(.66)$ & $.00(.70)$ & $.32(.65)$ & $-.01(.72)$ & 15 \\
\hline Math & $418(77)$ & $474(63)$ & $531(58)$ & $608(58)$ & $529(90)$ & 5 \\
\hline Read & $395(94)$ & 469 (74) & $529(67)$ & $594(62)$ & $520(97)$ & 5 \\
\hline Science & $418(92)$ & $484(73)$ & $551(65)$ & $613(60)$ & $539(96)$ & 4 \\
\hline \multicolumn{7}{|l|}{ Netherlands } \\
\hline Percent & 19 & 31 & 13 & 37 & & \\
\hline SES & $-.17(.83)$ & $.06(.82)$ & $.25(.75)$ & $.68(.75)$ & $.27(.86)$ & 7 \\
\hline Math & $429(55)$ & $486(55)$ & $538(51)$ & $605(47)$ & $526(86)$ & 7 \\
\hline Read & $414(50)$ & $466(57)$ & $523(51)$ & $588(51)$ & $508(86)$ & 7 \\
\hline Science & 417 (64) & $480(60)$ & $539(52)$ & $606(54)$ & $522(93)$ & 7 \\
\hline
\end{tabular}

Table 10. Cluster 2 of 4 for countries by school clusters: Percent of each school cluster, SES index, and Math, Reading, and Science score (standard deviation) for each school cluster

\begin{tabular}{|c|c|c|c|c|c|c|}
\hline & Lowest & Low & High & Highest & Total & Rank \\
\hline \multicolumn{7}{|l|}{ Finland } \\
\hline Percent & 0 & 7 & 78 & 15 & & \\
\hline SES & - & $.20(.76)$ & $.35(.77)$ & $.58(.75)$ & $.37(.78)$ & 3 \\
\hline Math & - & 494 (77) & $537(75)$ & $580(68)$ & 545 (77) & 3 \\
\hline Read & - & $489(83)$ & $532(82)$ & $578(72)$ & $536(83)$ & 1 \\
\hline Science & - & $506(83)$ & $551(83)$ & $597(76)$ & $554(85)$ & 1 \\
\hline \multicolumn{7}{|l|}{ Canada } \\
\hline Percent & 2 & 26 & 60 & 11 & & \\
\hline SES & $-.19(.79)$ & $.27(.82)$ & $.53(.79)$ & $1.00(.76)$ & $.50(.83)$ & 1 \\
\hline Math & $418(77)$ & 486 (77) & $537(75)$ & $592(69)$ & $527(83)$ & 6 \\
\hline Read & $409(81)$ & $483(84)$ & 534 (79) & $591(71)$ & $524(87)$ & 4 \\
\hline Science & $423(81)$ & $486(81)$ & $539(78)$ & $593(70)$ & 529 (86) & 5 \\
\hline
\end{tabular}


Table 11. Cluster 3 of 4 for countries by school clusters: Percent of each school cluster, SES index, and Math,

Reading, and Science score (standard deviation) for each school cluster

\begin{tabular}{|c|c|c|c|c|c|c|}
\hline & Lowest & Low & High & Highest & Total & Rank \\
\hline \multicolumn{7}{|l|}{ Singapore } \\
\hline Percent & 3 & 27 & 43 & 27 & & \\
\hline SES & $-.70(.78)$ & $-.73(.77)$ & $-.47(.77)$ & $-.01(.71)$ & $-.43(.80)$ & 19 \\
\hline Math & $451(89)$ & $505(83)$ & $534(85)$ & $648(74)$ & $562(100)$ & 1 \\
\hline Read & $412(86)$ & $471(78)$ & $521(81)$ & $604(72)$ & $526(95)$ & 3 \\
\hline Science & 417 (90) & $483(83)$ & $535(84)$ & $627(76)$ & $542(100)$ & 3 \\
\hline \multicolumn{7}{|l|}{ Germany } \\
\hline Percent & 21 & 23 & 27 & 29 & & \\
\hline SES & $-.42(.83)$ & $-.04(.80)$ & $.25(.78)$ & $.71(.80)$ & $.18(.90)$ & 10 \\
\hline Math & $404(64)$ & $478(62)$ & $533(61)$ & $603(58)$ & $513(95)$ & 10 \\
\hline Read & $393(68)$ & $465(65)$ & $521(60)$ & $580(54)$ & $497(92)$ & 13 \\
\hline Science & $406(70)$ & $488(65)$ & $544(61)$ & $610(59)$ & $520(97)$ & 8 \\
\hline \multicolumn{7}{|l|}{ Belgium } \\
\hline Percent & 18 & 28 & 30 & 25 & & \\
\hline SES & $-.46(.83)$ & $-.10(.84)$ & $.35(.84)$ & $.78(.79)$ & $.20(.93)$ & 69 \\
\hline Math & 398 (79) & $479(73)$ & $538(70)$ & $612(58)$ & $515(101)$ & 8 \\
\hline Read & $390(81)$ & $471(74)$ & $532(72)$ & $595(53)$ & $506(99)$ & 8 \\
\hline Science & $380(87)$ & $479(74)$ & $533(71)$ & $596(57)$ & $507(102)$ & 12 \\
\hline \multicolumn{7}{|l|}{ France } \\
\hline Percent & 27 & 21 & 28 & 24 & & \\
\hline SES & $-.61(.78)$ & $-.27(.76)$ & $-.03(.76)$ & $.38(.75)$ & $-.13(.84)$ & 17 \\
\hline Math & 398 (73) & $464(63)$ & $542(60)$ & $582(60)$ & 497 (98) & 13 \\
\hline Read & $387(84)$ & 468 (64) & $542(62)$ & $587(58)$ & $496(103)$ & 14 \\
\hline Science & $394(80)$ & $473(61)$ & $541(61)$ & $586(59)$ & 498 (99) & 16 \\
\hline \multicolumn{7}{|l|}{ Austria } \\
\hline Percent & 32 & 21 & 31 & 16 & & \\
\hline SES & $-.37(.77)$ & $-.08(.71)$ & $.34(.75)$ & $.58(.82)$ & $.06(.84)$ & 13 \\
\hline Math & $416(66)$ & $476(64)$ & $544(64)$ & $591(60)$ & $496(92)$ & 14 \\
\hline Read & $381(72)$ & 457 (67) & $526(66)$ & $561(61)$ & 470 (97) & 20 \\
\hline Science & 408 (77) & $481(68)$ & $546(70)$ & $587(63)$ & $494(98)$ & 18 \\
\hline
\end{tabular}

Table 12. Cluster 4 of 4 for countries by school clusters: Percent of each school cluster, SES index, and Math, Reading, and Science score (standard deviation) for each school cluster

\begin{tabular}{|c|c|c|c|c|c|c|}
\hline & Lowest & Low & High & Highest & Total & Rank \\
\hline \multicolumn{7}{|l|}{ Australia } \\
\hline Percent & 5 & 35 & 48 & 13 & & \\
\hline SES & $-.23(.75)$ & $.06(.69)$ & $.44(.70)$ & $.93(.64)$ & $.34(.75)$ & 4 \\
\hline Math & $426(77)$ & $477(82)$ & $529(78)$ & $593(75)$ & $514(89)$ & 9 \\
\hline Read & $408(88)$ & 477 (91) & $533(83)$ & $589(79)$ & $515(96)$ & 6 \\
\hline
\end{tabular}




\begin{tabular}{|c|c|c|c|c|c|c|}
\hline Science & $423(85)$ & $487(91)$ & $545(84)$ & $610(82)$ & $527(97)$ & 6 \\
\hline \multicolumn{7}{|l|}{ Switzerland } \\
\hline Percent & 6 & 41 & 32 & 21 & & \\
\hline SES & $-.43(.82)$ & $-.14(84)$ & $.14(.83)$ & $.58(.80)$ & $.08(.88)$ & 12 \\
\hline Math & 427 (77) & $492(82)$ & $550(73)$ & $626(61)$ & $534(94)$ & 4 \\
\hline Read & $403(74)$ & $462(80)$ & $513(72)$ & $589(57)$ & $500(90)$ & 10 \\
\hline Science & $412(76)$ & $477(80)$ & $531(72)$ & $606(60)$ & $517(92)$ & 9 \\
\hline \multicolumn{7}{|l|}{ Norway } \\
\hline Percent & 3 & 56 & 40 & 1 & & \\
\hline SES & $.07(.86)$ & $.37(.72)$ & $.62(.71)$ & $1.13(.55)$ & $.47(.74)$ & 2 \\
\hline Math & $425(70)$ & $482(78)$ & $524(75)$ & $596(61)$ & $498(80)$ & 12 \\
\hline Read & $420(89)$ & $486(85)$ & $532(82)$ & $597(61)$ & $503(88)$ & 9 \\
\hline Science & $420(76)$ & $482(82)$ & $529(79)$ & $608(60)$ & $500(85)$ & 14 \\
\hline \multicolumn{7}{|l|}{ United $\mathrm{K}$. } \\
\hline Percent & 9 & 48 & 34 & 9 & & \\
\hline SES & $-34(.74)$ & .02() & $.45(.74)$ & $.78(.68)$ & $.20(.79)$ & 8 \\
\hline Math & $421(81)$ & 469() & $521(71)$ & $585(58)$ & $492(83)$ & 16 \\
\hline Read & $416(93)$ & 472() & $523(80)$ & $588(62)$ & $494(92)$ & 17 \\
\hline Science & $422(93)$ & 488() & $549(80)$ & $611(65)$ & $514(95)$ & 10 \\
\hline \multicolumn{7}{|l|}{ Denmark } \\
\hline Percent & 5 & 54 & 37 & 4 & & \\
\hline SES & $-.29(.91)$ & $.14(.84)$ & $.54(.82)$ & $.85(.67)$ & $.30(.87)$ & 6 \\
\hline Math & $426(81)$ & $486(77)$ & $531(72)$ & $586(72)$ & $503(82)$ & 12 \\
\hline Read & $422(84)$ & $478(77)$ & $524(70)$ & $559(70)$ & $495(81)$ & 16 \\
\hline Science & 409 (87) & $480(83)$ & $531(76)$ & $586(82)$ & $499(88)$ & 15 \\
\hline \multicolumn{7}{|l|}{ Ireland } \\
\hline Percent & 11 & 41 & 47 & 1 & & \\
\hline SES & $-.50(.77)$ & $-.12(.79)$ & $.29(.81)$ & $1.04(.73)$ & $.05(.85)$ & 14 \\
\hline Math & $405(85)$ & $474(78)$ & $517(68)$ & $543(67)$ & 487 (82) & 18 \\
\hline Read & $401(96)$ & $480(87)$ & $530(76)$ & $582(74)$ & $496(92)$ & 15 \\
\hline Science & 415 (97) & $490(87)$ & $544(78)$ & $589(76)$ & $508(93)$ & 11 \\
\hline \multicolumn{7}{|l|}{ USA } \\
\hline Percent & 15 & 40 & 39 & 7 & & \\
\hline SES & $-.41(.83)$ & $-.10(.88)$ & $.49(.80)$ & $1.13(.63)$ & $.17(.93)$ & 11 \\
\hline Math & 409 (72) & 465 (74) & $524(72)$ & $581(67)$ & 487 (86) & 17 \\
\hline Read & $424(81)$ & $478(84)$ & $534(81)$ & $597(70)$ & $500(94)$ & 11 \\
\hline Science & $418(78)$ & $480(81)$ & $540(81)$ & $598(72)$ & $502(94)$ & 13 \\
\hline \multicolumn{7}{|l|}{ Sweden } \\
\hline Percent & 6 & 58 & 34 & 2 & & \\
\hline SES & $-.14(.90)$ & $.19(.78)$ & $.60(.76)$ & $.97(.66)$ & $.33(.81)$ & 5 \\
\hline Math & $407(80)$ & 479 (84) & $529(79)$ & $602(64)$ & 494 (89) & 15 \\
\hline Read & $417(95)$ & $480(92)$ & $534(82)$ & $602(64)$ & $497(96)$ & 13 \\
\hline
\end{tabular}




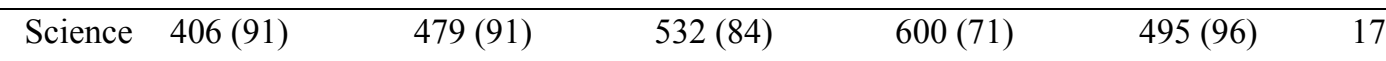

Spain

$\begin{array}{rllllll}\text { Percent } & 13 & 55 & 30 & 1 & & \\ \text { SES } & -.84(.99) & -.48(1.02) & .17(1.04) & 1.00(.74) & -.31(1.09) & 18 \\ \text { Math } & 418(83) & 475(82) & 525(72) & 587(61) & 483(87) & 19 \\ \text { Read } & 413(85) & 471(79) & 526(66) & 572(57) & 481(85) & 19 \\ \text { Science } & 423(83) & 479(78) & 531(69) & 583(58) & 488(84) & 19\end{array}$

Greece

$\begin{array}{rllllll}\text { Percent } & 23 & 50 & 26 & 1 & & \\ \text { SES } & -.62(.83) & .01(.96) & .43(.91) & .80(1.00) & -.02(.99) & 16 \\ \text { Math } & 390(70) & 475(70) & 514(69) & 563(58) & 466(83) & 20 \\ \text { Read } & 390(78) & 496(74) & 536(71) & 585(52) & 483(92) & 18 \\ \text { Science } & 385(72) & 479(70) & 525(67) & 590(49) & 470(86) & 20\end{array}$

\subsection{Students with Schools Analyses}

In addition to identifying the latent classes at both levels 1 and 2, and testing the impact of covariates at both levels, MLCA also allows for testing of the relationship between the within and between level latent class variables. In this case, the dependent variable was within level latent class membership and between level class membership was the independent. The results were statistically significant overall, indicating that membership in a given school latent class was associated with membership in a particular student latent class $(p<0.001)$. The cross tabulation of these variables appear in Table 13, while the slopes relating pairs of school and student latent classes appear in Table 14.

The overall pattern across nations was such that schools in relatively higher latent class categories had a greater percentage of students from the higher student latent class categories. In particular, the slope relating the Lowest school level to the Lowest student level was positive and significant, indicating that students in this level were significantly more likely than those in the Highest level to appear in the Lowest school category. A similar result was evident for the Low school and Lowest student classes, whereas for the High school and Lowest student the relationship was inverse. This suggests that students in the Lowest latent class were less likely than those in the Highest latent class to appear in the High school category. A similar pattern was in evidence for the Low student category, though the magnitude of the slopes was lower than for the Lowest student class. The relationships for the Median and High student classes were the converse, with each being more likely to appear in relatively higher performing schools, and the High group exhibiting stronger such relationships.

The relationships highlighted by the significant slopes from Table 14 can be further understood through a review of the cross-tabulations in Table 13.

Table 13. Percent of student latent class membership by school latent class and nation cluster

\begin{tabular}{llllll}
\hline \multirow{2}{*}{ Student class } & \multicolumn{2}{l}{ School class } & & High & Highest \\
\cline { 3 - 6 } \multicolumn{7}{l}{ Overall } & Lowest & Low & 1 & 0 \\
& Lowest & 31 & 7 & 11 & 1 \\
Low & 44 & 31 & 33 & 8 \\
Median & 21 & 40 & 41 & 42 \\
High & 4 & 19 & 14 & 49 \\
\multicolumn{1}{c}{ Cluster 1 Highest } & 0 & 3 & & \\
& Lowest & 29 & 5 & 0 & 0 \\
\hline
\end{tabular}




\begin{tabular}{rllll}
\hline Low & 44 & 30 & 8 & 0 \\
Median & 23 & 46 & 33 & 6 \\
High & 4 & 17 & 49 & 40 \\
Highest & 1 & 1 & 10 & 53
\end{tabular}

Cluster 2

$\begin{array}{rllll}\text { Lowest } & 27 & 7 & 1 & 0 \\ \text { Low } & 46 & 28 & 11 & 1 \\ \text { Median } & 22 & 39 & 31 & 10 \\ \text { High } & 5 & 23 & 41 & 39 \\ \text { Highest } & 0 & 4 & 17 & 49\end{array}$

Cluster 3

$\begin{array}{rllll}\text { Lowest } & 36 & 4 & 0 & 0 \\ \text { Low } & 45 & 31 & 6 & 1 \\ \text { Median } & 18 & 48 & 36 & 8 \\ \text { High } & 2 & 16 & 46 & 46 \\ \text { Highest } & 0 & 1 & 11 & 45\end{array}$

Cluster 4

$\begin{array}{rllll}\text { Lowest } & 30 & 8 & 1 & 0 \\ \text { Low } & 43 & 32 & 12 & 1 \\ \text { Median } & 22 & 37 & 32 & 11 \\ \text { High } & 5 & 20 & 38 & 38 \\ \text { Highest } & 0 & 4 & 16 & 49\end{array}$

Table 14. Parameter estimates for relationship between student and school level latent classes

\begin{tabular}{lrllll}
\hline \multicolumn{1}{l}{ Student level } & Slope & Standard error & Test statistic & $p$ \\
\hline Lowest & & & & & \\
& Lowest & 3.857 & 0.248 & 15.537 & 0.000 \\
& Low & 1.555 & 0.053 & 29.460 & 0.000 \\
& High & -1.864 & 0.065 & -28.604 & 0.000 \\
Low & & & & & \\
& Lowest & 2.227 & 0.102 & 21.758 & 0.000 \\
& Low & 0.828 & 0.038 & 21.828 & 0.000 \\
\multirow{4}{*}{ Median } & High & -0.944 & 0.053 & -17.446 & 0.000 \\
& & & & & \\
& Lowest & -1.918 & 0.080 & 24.094 & 0.000 \\
& Low & -0.672 & 0.054 & 12.389 & 0.000 \\
& High & 0.648 & 0.134 & -4.832 & 0.000 \\
& & & & & \\
& Lowest & -4.335 & 0.355 & -12.209 & 0.000 \\
& Low & -2.255 & 0.087 & -26.022 & 0.000 \\
& High & 2.824 & 0.086 & 32.815 & 0.000 \\
\hline
\end{tabular}


For example, it is clear that the Highest performing schools had virtually no students from either the Lowest or Low latent classes, and the Lowest performing schools had very few students from the two highest performing latent classes. With regard to the nation based clusters, several differentiated patterns emerged, within this larger framework. Clearly across all of the clusters, relatively lower performing students primarily attended lower performing schools. However, within this broader common pattern, there was some variation in student by school attendance patterns. For example, the Lowest performing schools in nation Cluster 3 demonstrated relatively fewer students above the Low category than did similar schools in the other clusters. In addition, the Highest school latent class had somewhat higher concentrations of students from either the High or Highest student latent classes, particularly in Cluster $1(93 \%)$ and to a lesser extent $3(91 \%)$, as compared to the same school type in Clusters $2(88 \%)$ and $4(87 \%)$. Similarly, the concentration of Low and Median performing students in the Low school class was somewhat greater for Clusters $1(76 \%)$ and $3(79 \%)$ than for $2(67 \%)$ and 4 (69\%). Finally, with regard to the Lowest school latent class, there was a somewhat greater concentration in the Lowest and Low student classes for Cluster 3 (81\%) than for any of the other clusters, each of which had $73 \%$ of students in the Lowest school class from the Lowest and Low student classes. Taken together, these results show that Cluster 3, and to a lesser extent Cluster 1, had a greater concentration of similarly performing students within schools than did either Cluster 2 or 4.

\section{Discussion}

As mentioned above, this study had two primary goals. The first was to demonstrate the great potential of nonparametric MLCA in simultaneously describing how individuals and groups of these individuals may be organized in the general population. This model extends upon the popular LCA framework by identifying latent classes at multiple levels (Asparouhov \& Muthén, 2008). This analytic framework is particularly well suited for educational research as it allows for investigation of organizational patterns at both the student and school levels, for example. In addition, the MLCA model also allows for the inclusion of covariates at both levels of analysis. In this study, the model included two student level covariates, native language and parental education, and three school level covariates, the average number of minutes, as reported by students, that were devoted to instruction in Language, Mathematics, and Science, respectively. These results can in turn be used to gain greater insights into the nature of the latent classes at both levels of analysis. Finally, the MLCA model provides a test for the relationship between the student and school level latent classes themselves. Thus in this case, rather than simply relying on a descriptive accounting of how students appear to be organized into schools, it is possible to ascertain inferentially whether membership in a given student latent class is significantly related to membership in a particular school class, as was demonstrated above. Therefore, we hope that this study has provided researchers with ideas for how they, too, can make use of this very powerful and flexible modeling tool.

As described previously, a second goal of this study was to obtain insights into how students are organized in schools within the 20 wealthiest nations participating in the PISA effort. Very often, the education systems of these nations are compared with one another only in terms of who has the highest mean achievement on one or more tests, perhaps controlling for SES. We look to extend that work with this study by identifying types of students and schools within these nations, in order to gain greater insights into how schools are organized. As noted, this is a salient feature of education performance that has been shown to be important within individual nations, but which has not been widely explored cross-nationally (Chia \& Xihua, 2008; Milford, Ross, \& Anderson, 2010). The resulting latent classes and nation clusters presented in this study provide deeper insights into both commonalities and differences with regard to the types of students based on both SES and achievement, how these students are organized into schools, and how such school organization might be similar and different across nations. In this way, we have been able to demonstrate the clear link between type of school and academic achievement and SES. In addition, we have also shown that such organization is both not consistent across nations, and has a direct relationship with student achievement. Researchers and policy makers might use these results as a first step to begin considering how similar and divergent profiles might impact educational attainment, and how different education systems have attempted to modify or address these populations and school organization patterns.

Perhaps the most notable outcome of the student level analysis was that the cluster of nations with the highest mean achievement also had the lowest mean SES, and the cluster with the lowest overall mean achievement had the second highest mean SES value. Despite this relative lack of financial resources, students in this cluster performed very well on each of the three achievement measures, regardless of student latent class. Additionally, hese highest achieving nations also had the greatest concentration of the highest SES/achievement schools and the best performance in the highest category of schools, even while their students in somewhat lower performing schools had comparable mean achievement scores to the other nations included in the study. These results extend 
earlier research suggesting that a high concentration of relatively high performing and high SES students was associated with better achievement for these individuals, while a high concentration of lower performing/SES students led to low achievement for these individuals (Alegre \& Ferrer, 2010). The current study places these findings in the context of national school organization such that nations whose highest performing students are clustered together in high performing schools can expect to see relatively better academic performance than nations in which students of varying performance levels are grouped together.

A second major finding of this research is that high national academic achievement can also be associated with a relatively equitable distribution of students into schools. The countries in cluster 2 in this study included a full $83 \%$ of all schools in one of the two middle latent classes, and yet displayed the highest mean achievement for math and science in the lowest and low groups. In other words, their low schools were not as low as those in other country clusters, further supporting the idea that lower achieving students are benefited by being mixed with higher achievers. This result is of particular interest in light of prior findings that demonstrated the great impact on overall mean achievement of student mixture vis-à-vis SES and achievement levels within schools (e.g., Dronkers \& Levels, 2007). In contrast, nations whose lowest performing students were more isolated into low performing schools consistently underperformed other nations' lowest performing students, particularly in math and reading. However, the high achievers in these nations displayed comparable performance to high achievers in other countries, again supporting the notion that when schools are relatively homogeneous with regard to the types of students they contain, low achievers tend to perform worse and high achievers tend to perform better (De Fraine, van Damme, van Landeghem, Opdenakker, \& Onghena, 2003).

\section{Conclusions}

Clearly, simple comparisons of nations based on test scores provide a simplistic and likely invalid indicator of educational quality because students at differing levels of achievement and SES are differentially organized across countries, and this study demonstrates that with whom students attend school is related to their academic performance. The nonparametric MLCA employed here served as an ideal tool for demonstrating this point by providing insights into how students and schools are organized across the world, as well as by identifying factors that are associated with this school organization. Based on these results, the ways in which schools are organized is clearly associated with differing levels of student performance. Furthermore, individual nations have their own specific ways in which students and schools are distributed, and this organization strategy in turn impacts overall metrics of performance. Indeed, even within a similar type of school or for similar types of students (e.g., higher performers), different clusters of nations manifested different levels of test performance and SES. Therefore, to simply say that nation A is relatively poor and has relatively low achievement does not speak to the great variation that was identified by this study. More meaningful questions might be, "What is the academic achievement of relatively poor students in nation A when compared to similar students in other nations, and with whom are these relatively poor students attending school?" Likewise, the results presented here point to the importance of considering the relative performance and available resources for lower and higher performing schools within different types of countries, rather than simply pointing to some overall measure of school performance that ignores the great variegation in how schools are organized from country to country. For example, knowing that the students Finland look more like the students in the Netherlands than those in Sweden or Norway is a start. Knowing that Finnish schools look nothing like those of any other countries' also helps. Knowing that countries with similar types of students in terms of SES and parental education, but who attend schools with very different configurations have differential achievement provides insights into the "spirit" of success that makes a difference. Understanding how this "spirit" translates into educational policy may facilitate improvements for countries, schools, and students.

\subsection{Limitations and Future Research}

As with any research, there are limitations inherent in the current study. For example, data were only examined for the 20 wealthiest nations participating in PISA. While there were certainly differences among them in terms of SES and parental education, for example, it is also true that such differences pale in comparison to those between them and the poorest participating countries. For this reason, future research should include a wider variety of nations, perhaps even focusing on the poorer PISA participants. A second limitation was the relatively small number of covariates that were included in the analysis. Those that were included were selected because prior research has demonstrated them to be salient predictors of academic achievement. However, there are certainly more such variables that could serve a similar role, and whose inclusion in the study would help to further explain cross-national, cross-school, and cross-individual differences in academic performance. Such variables might include the number of academic resources available in the home (i.e., books, magazines, computers), the students' scores on measures of academic engagement and affect toward the teachers, and the 
students' use of educational resources outside of the classroom such as tutoring services. A third limitation of the current study is that it was not able to take into account the educational policies of the nations included in the analysis. While such policies are certainly available for study, their great complexity makes it difficult, if not impossible, to quantify them in any meaningful way and thereby include them in the analysis. Furthermore, the inclusion of a relatively large number of nations makes describing the policies of each in the current manuscript impractical. Nonetheless, future research could perhaps focus on a small number of nations and include information about their relevant educational policies in the discussion of the results.

With regard to the statistical analyses used here, the power of the nonparametric MLCA model has been demonstrated. This approach allows for the simultaneous grouping of individuals and groups of individuals. It also easily incorporates covariates at both levels of analysis, and allows for explicit testing of the relationship between latent class membership at these multiple levels. We would suggest that in the context of educational research, this model opens up a panoply of research opportunities. For example, scholars can use it to investigate not only 2-level models such as the one featured here, but cases where data are organized into 3 or more steps of hierarchy. Thus, one could examine how student achievement is organized with regard to students within teachers within schools. $\mathrm{n}$ addition, the inclusion of covariates at each level of analysis provides for the opportunity to truly understand the nature of these latent classes. Future work with this model should emphasize take full advantage of this capability. Finally, this model can accommodate multidimensional, as well as multilevel latent structure. Therefore, it would be possible to simultaneously model multiple factors using the observed indicator variables, and in turn use these factors to identify the latent classes at multiple levels. We hope that the current work serves as a first step in the increased use of this powerful and flexible modeling framework in the area of international educational research.

\section{References}

Abella, R., Urrutia, J., \& Shneyderman, A. (2005). An examination of the validity of English-language achievement test scores in an English language learner population. Bilingual Research Journal, 29, 127-144. http://dx.doi.org/10.1080/15235882.2005.10162827

Abedi, J., \& Lord, C. (2001). The language factor in mathematics tests. Applied Measurement in Education, 14(3), 219-234. http://dx.doi.org/10.1207/S15324818AME1403_2

Alegre, M. H., \& Ferrer, G. (2010). School regimes and education equity: Some insights based on PISA 2006. British Education Research Journal, 36(3), 433-461. http://dx.doi.org/10.1080/01411920902989193

Asparouhov, T., \& Muthén, B. (2008). Multilevel mixture models. In G. R. Hancock, \& K. M. Samuelsen (Eds.), Advances in latent variable mixture models (pp. 27-51). Charlotte, NC: Information Age Publishing, Inc.

Caldas, S. J., \& Bankston, C. (1997). Effect of school population socioeconomic status on individual academic $\begin{array}{lllll}\text { achievement. Journal of } & \text { Education }\end{array}$ http://dx.doi.org/10.1080/00220671.1997.10544583

Chiu, M. M., \& Xihua, Z. (2008). Family and motivation effects on mathematics achievement: Analyses of students in 41 countries. Learning and Instruction, 18, 321-336. http://dx.doi.org/10.1016/j.learninstruc.2007.06.003

De Fraine, B., Van Damme, J., Van Landeghem, G., Opdenakker, M. C., \& Onghena, P. (2003). The effect of schools and classes on language achievement. British Educational Research Journal, 29(6), 841-859. http://dx.doi.org/10.1080/0141192032000137330

Dronkers, J., \& Levels, M. (2007). Do school segregation and school resources explain region-of-origin differences in the mathematics achievement of immigrant students? Educational Research and Evaluation, 13, 435-462. http://dx.doi.org/10.1080/13803610701743047

Equity Trust. (2010). Retrieved June 1, 2011 from http://www.equalitytrust.org.uk/

Gordon, A. D. (1999). Classification. Boca Raton, FL: Chapman \& Hall/CRC.

Hakkinen, I., Kirjavainen, T., \& Uusitalo, R. (2003). School resources and student achievement revisited: New evidence from panel data. Economics in Education Review, 22, 329-335. http://dx.doi.org/10.1016/S0272-7757(02)00060-2

Henry, K. L., \& Muthén, B. (2010). Multilevel latent class analysis: An application of adolescent smoking typologies with individual and contextual predictors. Structural Equation Modeling, 17, 193-215. http://dx.doi.org/10.1080/10705511003659342 
Hoijtink, H. (2001). Confirmatory latent class analysis: Model selection using Bayes factors and (pseudo) likelihood ratio statistics. Multivariate Behavioral Research, 36, 563-588. $\mathrm{http}: / / \mathrm{dx}$. doi.org/10.1207/S15327906MBR3604_04

Kaufman, L., \& Rousseeuw, P. J. (2005). Finding groups in data: An introduction to cluster analysis. Hoboken, NJ: John Wiley \& Sons, Inc.

Lupton, R. (2005). Social justice and school improvement: Improving the quality of schooling in the poorest neighbourhoods. British Educational Research Journal, 31(5), 589-604. http://dx.doi.org/10.1080/01411920500240759

Ma, X., Ma, L., \& Bradley, K. D. (2008). Using multilevel modeling to investigate school effects. In A. A. O'Connell, \& D. B. McCoach (Eds.), Multilevel modeling of educational data. Charlotte, NC: Information Age Publishing.

Mansell, W. (2011). What is it about Finland? Education Journal, 127, 24-25.

Milford, T., Ross, S. P., \& Anderson, J. O. (2010). An opportunity to better understand schooling: The growing presence of PISA in the Americas. International Journal of Science and Mathematics Education, 8(3), 453-473. http://dx.doi.org/10.1007/s10763-010-9201-z

Muthén, L. K., \& Muthén, B. O. (2011). Mplus User's Guide, version 6.11. Los Angeles: Author.

Opdenakker, M. C., \& Van Damme, J. (2001). Relationship between school composition and characteristics of school process and their effect on mathematics achievement. British Educational Research Journal, 27(4), 407-432. http://dx.doi.org/10.1080/01411920120071434

Organization for Economic Cooperation and Development. (2009). PISA 2009 Assessment Framework: Key competencies in reading, mathematics and science. Retrieved July 20, 2011, from http://www.oecd.org/document/44/0,3746,en_2649_35845621_44455276_1_1_1_1,00.html

Organisation for Economic Co-operation and Development (OECD). (2007). PISA 2006: Science competencies for tomorrow's world (Vol. 1: Analysis) (Paris, OECD).

Ravitch, D. (2012). Schools we can envy. The New York Review of Books. Retrieved February 24, 2012, from http://www.nybooks.com/articles/archives/2012/mar/08/schools-we-can-envy/

Rubenstein, R. (2012, Feb. 19). Finnish far ahead of U.S. schools. The Register-Guard (pp. G1). Retrieved February 23, 2012, from http://special.registerguard.com/web/opinion/27609041-47/finland-schools-students-education-finnish.html. $\operatorname{csp}$

Schreiber, J. B. (2002). Institutional and student factors and their influence on advanced mathematics achievement. Journal of Educational Research, 95, 274-286. http://dx.doi.org/10.1080/00220670209596601

Vermunt, J. K. (2008). Latent class and finite mixture models for multilevel data sets. Statistical Methods in Medical Research, 17, 33-51. http://dx.doi.org/10.1177/0962280207081238 